\title{
Simulation of the Control of a Salt Gradient Solar Pond in the South of Tunisia
}

\author{
M. Ouni ${ }^{1}$, A. Guizani ${ }^{2}$ and A. Belghith ${ }^{1}$ \\ ${ }^{1}$ Unité de Transfert de Chaleur et de Masse, Département de Physique, Faculté des Sciences, 1060 Tunis, Tunisie \\ 2 INRST, B.P.95, 2050 Hammam Lif, Tunisie
}

\begin{abstract}
We are interested in modelling and control of a salt gradient solar pond (SGSP) in the south of Tunisia. We developed a model of a Closed Cycle Salt Gradient Solar Pond (CCSGSP) that ensure successful year round operation of the pond. This model was used to study the response of solar pond (SP) to various control technique. It takes into account heat and salt diffusion in the pond and simulates the transient behaviour of a SGSP. Furthermore, we investigated the dynamic process, which involve internal gradient stability, boundary behaviour between gradient zone and convective zones. We thus incorporated the double diffusive processes into the SP model by using the one dimensional stability criterion produced by linear theory. The governing differential equations are solved with a fully implicit technique described by Patankar. The results show that successful operation of a SP requires three things: the maintenance of the storage zone temperature through heat extraction and brine injection, the use of surface washing to control the deepening of the upper mixed layer and a well designed initial salt stratification to prevent the formation of instability within the gradient. Using linear salinity profile as an initial condition, three-year simulations were run using average meteorological data with the result that adequate stability ( $R \rho>2$ throughout the gradient and $R \rho \cong 10$ at the interfaces) was maintained and during the entire year. Numerical results show also that $15 \%-30 \%$ efficiency could have been expected if heat extraction is performed routinely especially when one considers that the storage temperature is within $40-80^{\circ} \mathrm{C}$.
\end{abstract}

Keywords: Solar energy - Solar pond - Salt gradient - Double diffusion.

\section{INTRODUCTION}

In recent years, there is an increase in the efforts to promote renewable energy in developing countries. Solar pond (SP) is one such technology, which is both appropriate and relevant in the Tunisian context. Salinity gradient solar ponds (SGSPs) are essentially low cost solar collectors with integrated storage, and hence are potential, cheaper alternatives to flat plate collectors system in suitable location [5].

In Tunisia, the history of the study of the SP is not so long [7]. In the south of Tunisia, the high insulation (approx. $18 \mathrm{MJ} / \mathrm{m}^{2}$ days) and the existence of the vast arid zones near the Mediterranean sea make favourable environment for the development of SPs. The reserves of natural brine in this part are estimated to several millions of cubic meters [3]. In this areas where salt is available at low cost and brine can easily be discarded without causing environmental problems, recycling the salt becomes mandatory. Since this site has a relatively high net evaporation, salt recycling may be achieved by natural evaporation of brine in an evaporation pond (EP). The initial aim of this work is to show the feasibility study for installing a $17000 \mathrm{~m}^{2} \mathrm{SP}$ for supplying process heat to a desalination plant in the locality of El Bibane in the south of Tunisia. Previously, thermal performance was discussed by Ouni et al. [7].

Many of the fundamental physical processes important to the dynamics of a SP were described initially by Weinberger [14] who also described the stability criterion for double diffusive systems with linear gradients. Xu discussed thoroughly SP stability and other dynamical processes [15]. Tabor and Nielsen provide good general reviews of SP Technology [9, 13]. Related works were reported by Witte and Newell [12], Zangrando [16]. Hull et al. [4] discussed in detail SP thermal performance and Alagao has developed a model for a CCSGSP and discussed different modes of salt recycling [1].

This paper describes the transient behaviour of SPs with complete salt recycling system using natural evaporation of brine in an EP. Also, we investigated the dynamic process, which involve internal gradient stability, boundary behaviour between gradient zone and convective zones.

We have incorporated the double diffusive processes into the SP model. We use the one dimensional stability criterion produced by linear theory. We have developed a model of a Closed Cycle Salt Gradient Solar Pond (CCSGSP) that ensure successful year round operation of the pond. This model was used to study the response of SP to various control techniques. A computer program, which could calculate the temperature and salinity rise in the pond, is developed. 


\section{OPERATING AND CONTROL PRINCIPLE OF A SOLAR POND}

A SP is a basin of water where a salinity gradient is artificially created in order to prevent the convection induced by the absorption of solar radiation. In a SP there are typically three well-defined zones, as shown in figure1. The surface or upper convective zone (UCZ) and storage or lower convective (LCZ) zone are convective zones where the temperature and salinity can be considered uniform. In the gradient zone or nonconvective zone (NCZ) the salt gradient prevents convection and, as a result of solar energy absorption, a gradient of temperature is established. Water being a poor conductor of heat, the gradient zone functions as a transparent insulation so that the heat absorbed is trapped and stored in the storage zone. The buoyancy effect is balanced by the weight of water so that solar radiation is converted into sensible heat .The temperature in the storage zone can reach an average of $90^{\circ} \mathrm{C}$. This amount of heat can be stored for a long period and temperature decreases slowly if the pond is well sized. Heat extraction can be done either by submerged heat exchangers or by heat exchangers placed outside the pond, in which case hot brine from the pond is circulated through the external heat exchanger and pumped back to the storage zone. The ability of a pond to collect and store heat in the lower layer depends on the establishment of a stabilising salinity gradient to suppress natural thermal convection.

SP operation is dependent on weather conditions and on the physical and chemical characteristics of the brine. Evaporation and rainfall affect the salinity and depth of the SP and its thermal output depends on the available radiation. Salt diffusion from the bottom of the LCZ through the gradient to the surface increases the salinity of the UCZ and at the same time decreases the salinity of the LCZ. UCZ must be kept as low as practical and the LCZ salinity high enough to maintain a gradient that can sustain stable pond operation at high operating temperatures. Maintenance of the salinity profiles involves addition of salt or concentrated brine at the LCZ and fresh water lower salinity brine flushing at the UCZ. Since the site of El Bibane has a relatively high net evaporation, salt recycling may be achieved by natural evaporation of brine in an EP and injection of the concentrated brine into the SP LCZ.

Figure 1 shows the schematic of a CCSGSP. Closed cycle operation of SPs, apart from being simple, offers a more stable, long- term SP operation.

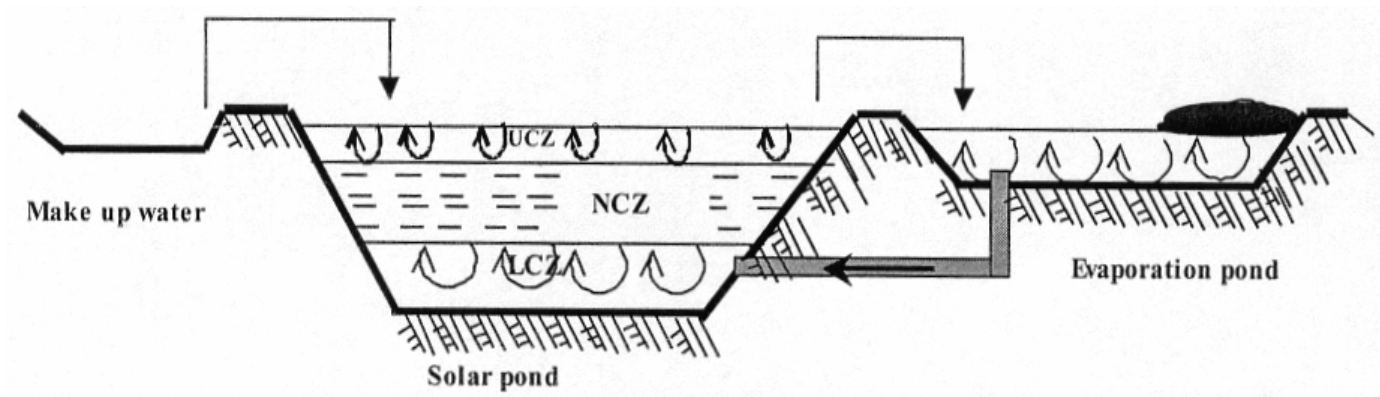

Fig. 1: Schematic of a closed cycle salt gradient solar pond

\section{STABILITY OF THE GRADIENT ZONE}

A SGSP works as a collector and storage system because the stratified layer acts as a transparent insulator. If this layer is not maintained stratified over the design thickness, then the SP thermal performance can drop sharply. The gradient zone is a double diffusive layer of salt and temperature. Since the diffusivities of these two components are quite different, instabilities of the double diffusive type may occur and may lead to steady convective motions, therefore decreasing the insulation properties of the layer [17]. The main problem of a SP is thus to maintain the non-convectivity of the gradient zone and its stability.

Double diffusive systems such as SP are generally characterised by four dimensionless parameters: the thermal Rayleigh number, $\mathrm{Ra}=\mathrm{g} \alpha \Delta \mathrm{Th}^{3} / \nu \kappa_{\mathrm{T}}$; a salinity Rayleigh number $\mathrm{Rs}=\mathrm{g} \beta \Delta \mathrm{Sh}^{3} / \nu \kappa_{\mathrm{T}}$; the Prandt number, $\operatorname{Pr}=v / \kappa_{\mathrm{T}} ;$ and the ratio of the diffusivities of the stratifying species, $\tau=\mathrm{D} / \kappa_{\mathrm{T}} ; \alpha\left({ }^{\circ} \mathrm{C}^{-1}\right)$ and $\beta\left(\%^{-1}\right)$ are the coefficients of thermal and saline expansion given by $\alpha=-\frac{1}{\rho} \frac{\partial \rho}{\partial \mathrm{T}}$ and $\beta=\frac{1}{\rho} \frac{\partial \rho}{\partial \mathrm{S}}$.

The ratio of the two Rayleigh numbers, the stability number, $R \rho=\frac{R a}{R s}=\frac{\beta \Delta S}{\alpha \Delta T}$, is used commonly to describe the stability of the system. As R $\rho$ increases, the stabilising salinity gradient becomes relatively stronger, reducing the possibility of instability forming. Veronis, Sechester and Turner [2], provided the basis for 
stability studies in double diffusive system,namely thermohaline convection in SPs. In the absence of double diffusive problems, the criteria for stability of a gradient layer is obtained by setting $\partial \rho / \partial x<0$, which leads to Rs $>$ Ra. According to Veronis [2], a layer of fluid with both gradients of salt and temperature heated from below is maintained stable (non- convective) if :

$$
\operatorname{R} \rho>\frac{\operatorname{Pr}+1}{\operatorname{Pr}+\tau}
$$

For typical values of Pr and $\tau$ in SP, one can obtain $\mathrm{R} \rho>1.14$. Giestas et al. [2] analysed the stability of the gradient zone of a SP, taking in account solar radiation absorption in the gradient layer. The results shown are in good agreement with the previous results obtained by Veronis.

Two theories $[9,10]$ have been proposed for interfacial stability to double diffusive effects. Both recover the same critical stability condition (no net erosion/growth at the interface) :

$$
\mathrm{R} \rho=\left(\frac{\mathrm{k}_{\mathrm{T}}}{\mathrm{D}}\right)^{1 / 2}=\tau^{-1 / 2}
$$

This condition results from a balance between the contribution to the net density from temperature and from salinity in the diffused profiles, at the height coincident with the original interface height. For large R $\rho$, the stratification grows at the expense of the mixed layer; for smaller R $\rho$ the stratification is eroded. For sodium chloride and SP conditions ( $\tau \cong 0.01$ ) equilibrium condition occurs when $R \rho=\tau^{-1 / 2}$ is about 10 [17].

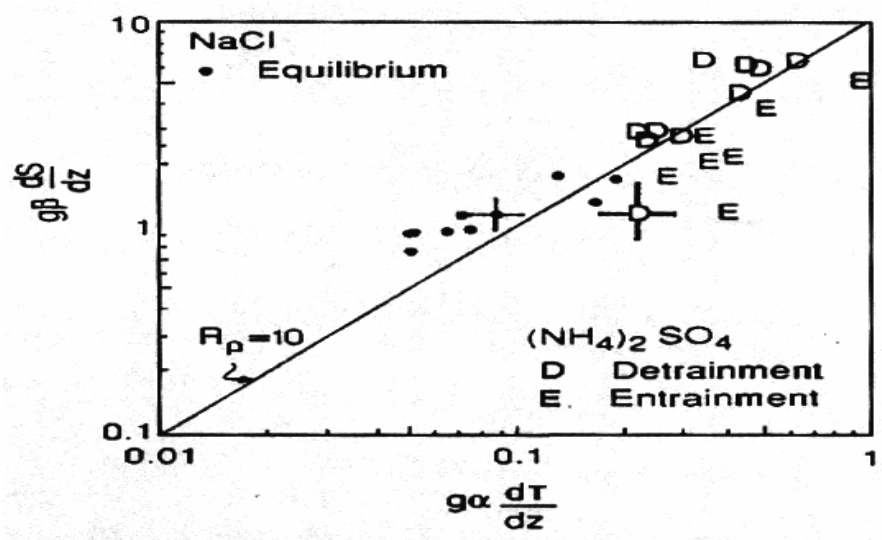

Fig. 2: Contribution to the net density gradient in solar ponds and laboratory tanks measured near boundary. Dots represent equilibrium data for sodium Chloride. Nonequilibrium data for ammonium sulphate stratification's represent cases of entrainment (E) and detrainment (D) at the boundary [17].

Both theories provide estimates of entertainment/detrainment rates, however, no data exist that are sufficiently accurate to verify the rate of interfacial movement of these slow entertainment conditions. Equation (2) predicts reasonably well interfacial stability conditions obtained with sodium chloride and ammonium sulphate salts over a broad range of $\mathrm{R} \rho$, as shown in figure 2 [17].

\section{TRANSIENT BEHAVIOUR}

The pond is considered to be very large. Therefore the side effects, namely, the convection currents at the sides are ignored. The temperature and salinity of the UCZ and LCZ are considered to be uniform. The thickness of the NCZ and LCZ are uniform in time as well as over the pond area. The surface layer is allowed to vary in a specified range. It is assumed that the energy extraction does not disturb the NCZ-LCZ interface. The properties of SP brine are assumed to vary only in vertical direction.

The rising pond method to configure the salinity profile was discussed by Hull and Nielsen [4]. Concentrated brine injection at the top of the LCZ gives the entire $\mathrm{NCZ}$ an upward vertical velocity with the following effects [1]:

i) salinity gradient at the upper interface and the layers close below it are strengthened;

ii) salinity gradient at the lower interface and the layers close above it are weakened; 
iii) salt transport is increased;

iv) bottom heat loss is slightly increased due to the introduction of cold brine into the pond LCZ from the EP.

The salinity profile is calculated using species balances of salt in every layer :

LCZ :

$$
\mathrm{AH}_{3} \frac{\partial \mathrm{C}_{\mathrm{L}}}{\partial \mathrm{t}}=\phi_{\text {inj }}-\phi_{\text {diff }}-\phi_{\mathrm{vL}}-\phi_{\text {ext }}
$$

$\mathrm{NCZ}$ :

$$
\frac{\partial \mathrm{C}}{\partial \mathrm{t}}=\frac{\partial}{\partial \mathrm{x}}\left[\mathrm{D}\left(\frac{\partial \mathrm{C}}{\partial \mathrm{x}}\right)\right]-\mathrm{V}\left(\frac{\partial \mathrm{C}}{\partial \mathrm{x}}\right)
$$

$\mathrm{UCZ}$ :

$$
\mathrm{AH}_{1} \frac{\partial \mathrm{C}_{\mathrm{u}}}{\partial \mathrm{t}}=\phi_{\mathrm{mw}}+\phi_{\text {diff }}+\phi_{\mathrm{Lv}}-\phi_{\mathrm{of}}
$$

The coefficient of salt diffusivity $\mathrm{D}$ is given by [17] :

$$
\mathrm{D}=\left(0.58+0.0030 \mathrm{~T}+0.0002 \mathrm{~T}^{2}+0.001 \mathrm{~S}^{2}\right) 10^{-9} \quad \mathrm{~m}^{2} / \mathrm{s}
$$

The distribution of temperature in the three zone are given by an energy balance :

$$
\mathrm{A}_{\mathrm{SP}} \mathrm{H}_{1} \rho \mathrm{C}_{\mathrm{p}} \frac{\partial \mathrm{T}_{\mathrm{U}}}{\partial \mathrm{t}}=\left(\sum \phi_{\mathrm{in}}^{\mathrm{SP}}-\sum \phi_{\mathrm{out}}^{\mathrm{SP}}\right)
$$

$$
=\left[\phi_{\mathrm{I}}+\phi_{\mathrm{vu}}+\phi_{\mathrm{mw}}+\phi_{\mathrm{cond}}+\phi_{\mathrm{ran}}\right]-\left[\phi_{\mathrm{of}}+\phi_{\mathrm{g}}+\phi_{\mathrm{conv}}+\phi_{\mathrm{ev} \alpha}+\phi_{\mathrm{rad}}\right]
$$

LCZ :

$$
\frac{\partial \mathrm{T}}{\partial \mathrm{t}}=\frac{\partial}{\partial \mathrm{x}}\left[\mathrm{k}\left(\frac{\partial \mathrm{T}}{\partial \mathrm{x}}\right)\right]-\mathrm{V} \frac{\partial \mathrm{T}}{\partial \mathrm{x}}+\frac{\mathrm{q}_{1}}{\rho \mathrm{C}_{\mathrm{p}}}-\frac{\mathrm{q}_{\mathrm{g}}}{\rho \mathrm{C}_{\mathrm{p}}}
$$

$$
\mathrm{A}_{\mathrm{SP}} \mathrm{H}_{3} \rho \mathrm{C}_{\mathrm{p}} \frac{\partial \mathrm{T}_{\mathrm{L}}}{\partial \mathrm{t}}=\left(\sum \phi_{\mathrm{in}}^{\mathrm{SP}}-\sum \phi_{\mathrm{out}}^{\mathrm{SP}}\right)_{\mathrm{L}}=\phi_{1}-\left[\phi_{\mathrm{ext}}+\phi_{\mathrm{vL}}+\phi_{\mathrm{g}}\right]
$$

The EP is supposed completely convective, its temperature is given by :

$$
\begin{aligned}
\mathrm{A}_{\mathrm{EP}} \mathrm{H}_{\mathrm{EP}} \rho_{\mathrm{EP}} \mathrm{C}_{\mathrm{p}_{\mathrm{EP}}} \frac{\partial \mathrm{T}}{\partial \mathrm{t}} & =\left(\sum \phi_{\text {in }}^{\mathrm{EP}}-\sum \phi_{\text {out }}^{\mathrm{EP}}\right) \\
= & {\left[\phi_{\mathrm{of}}+\phi_{\text {ran }}+\phi_{1}\right]-\left[\phi_{\text {inj }}+\phi_{\text {evap }}+\phi_{\text {conv }}+\phi_{\text {rad }}+\phi_{\mathrm{g}}\right] }
\end{aligned}
$$

The EP and SP depths are calculated using volume balance :

$$
A_{E P} \frac{\partial H_{E P}}{\partial t}=-\mathrm{VA}_{S P}-A_{E P} E_{E P}+Q_{o f} ; A_{S P} \frac{\partial H_{S P}}{\partial t}=V_{S P}-A_{S P} E_{S P}+Q_{m w}-Q_{o f}
$$

The model suggested by Rabl and Nielsen and validated by Wang and Yagoobi, is adopted to evaluate the radiation attenuation in the pond [13].

The simulation of the transient behaviour of the SGSP is done using the numerical method of the finite volume. The LCZ and the UCZ are assumed two distinct layers and the NCZ is divided into N uniformly layers of equal thickness. The salinity and temperature at the node $\mathrm{j}$ in the NCZ is obtained from those at the adjacent nodes by a fully implicit discretisation of equations (4) and (8) using the technique described by Patankar [8].

\section{SIMULATION OF THE PERFORMANCE OF A SOLAR POND}

The performance of a SP, which uses solar energy as the heat source, is affected by the weather conditions prevailing in the SP site. Among the meteorological parameters, which affect the performance of SP, are the solar radiation, ambient temperature, wind velocity, humidity and rainfall. These parameters are subject to continuous change from hour to hour. A weather data file was created using the measured data covering the period of the year of 1994, and used as in input in the computer model. Figure 3 shows the profile development of meteorological data for El Bibane. 
In order to simulate the operating performance of such SP to some degree of accuracy, a computer-based program is indispensable. Three years simulation of SGSP operation wasdone for El Bibane. El Bibane lies approximately on the $33^{\circ} 88$ latitude and $10^{\circ} 10$ longitude. Furthermore, the information about the depth of the pond, the physical properties of brine must be provided. In the simulation the normal UCZ thickness was taken to $0.3 \mathrm{~m}$, the $\mathrm{NCZ} 1.2 \mathrm{~m}$ and the $\mathrm{LCZ} 1 \mathrm{~m}$. The $\mathrm{NaCl}$ is the assumed salt in the model and all physical properties of $\mathrm{NaCl}$ solution are treated as functions of salinity and/or temperature. The thermal conductivity of the ground was assumed to be $1 \mathrm{Wm}^{-1} \mathrm{C}^{-1}$. Wave suppressing nets were assumed used at the surface and therefore the effect of the wind at the UCZ is neglected.
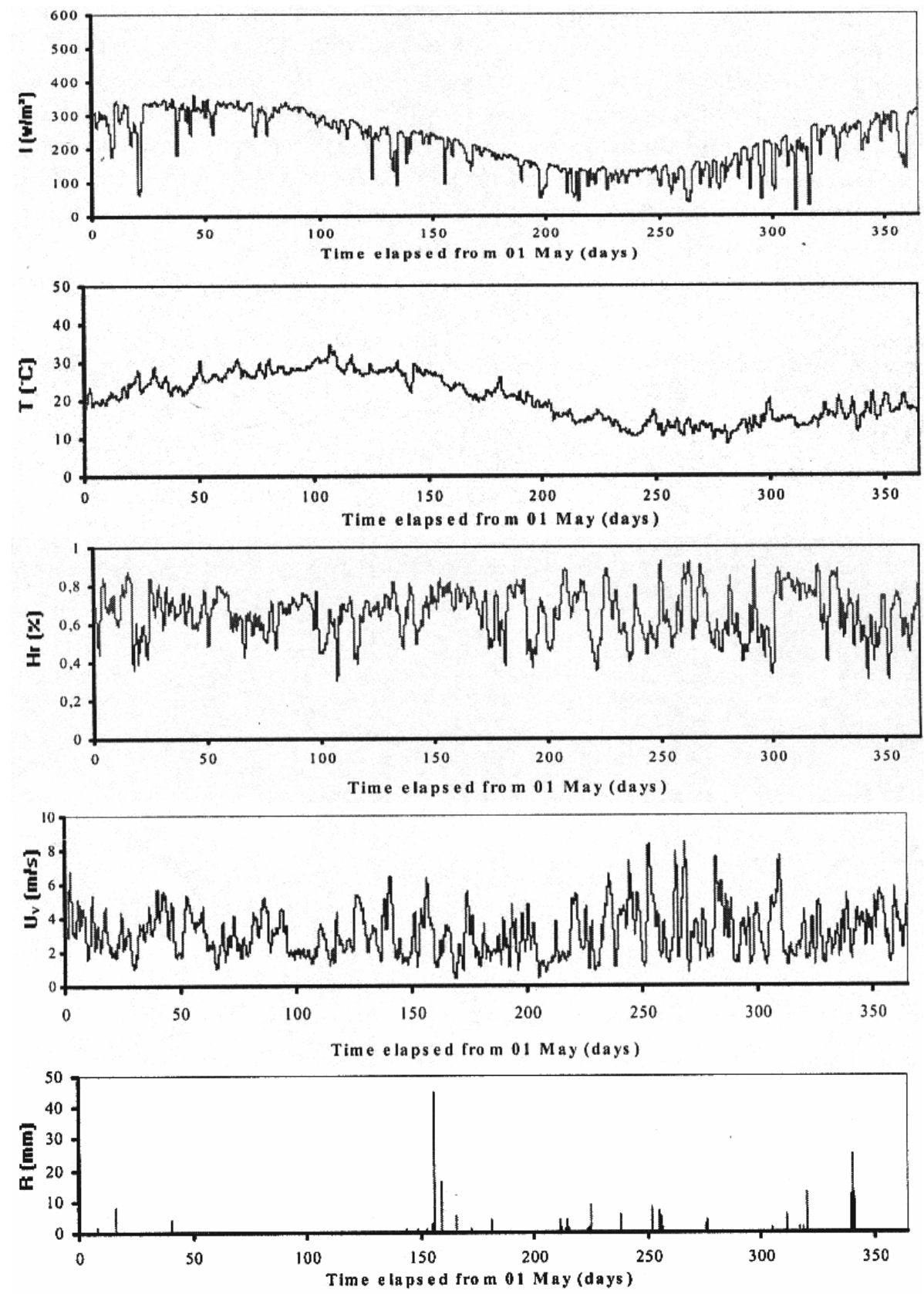

Fig. 3: Climate data for El Bibane

a- Mean daily solar radiation flux; b- Ambient temperature c- Relative humidity; d- Wind speed, e- rainfall

\section{RESULTS AND DISCUSSIONS}

Results were obtained from the simulation of the operation of (CCSGSP) during a period of three years. Calculation starts on the 1 May, assuming uniform initial temperature field throughout the SP. The initial salinity 
of the UCZ and the LZC are equal respectively to $2 \%$ and $25,5 \%$ per weight. A space step $\Delta \mathrm{x}=0.01 \mathrm{~m}$ has been selected with a time step $\Delta \mathrm{t}=3600 \mathrm{~s}$.

From figure 4, indicating the SP temperature development, it is observed that large temperature gradients occur at the lower interface during the initial SP operation, rendering the interface unstable. Figure 5 shows the SP salinity development. It indicates clearly the existence of salt diffusion from the storage zone to the surface layer. Two mechanisms participate to this transfer: molecular diffusion and the upward movement of the NCZ due to brine injection at the LCZ. The quantity of salt transferred by molecular diffusion is estimated to 20 $\mathrm{kg} / \mathrm{m}^{2} /$ year. Nielsen reported that the salt diffused in the Ohio State SP is estimated to $60-70 \mathrm{~kg} / \mathrm{m}^{2} /$ day [9]. This salt must be extracted from the UCZ and recycled externally in an EP. In order to maintain the salinity of the surface in appropriate value and to control the deepening of the UCZ, fresh water must be added.

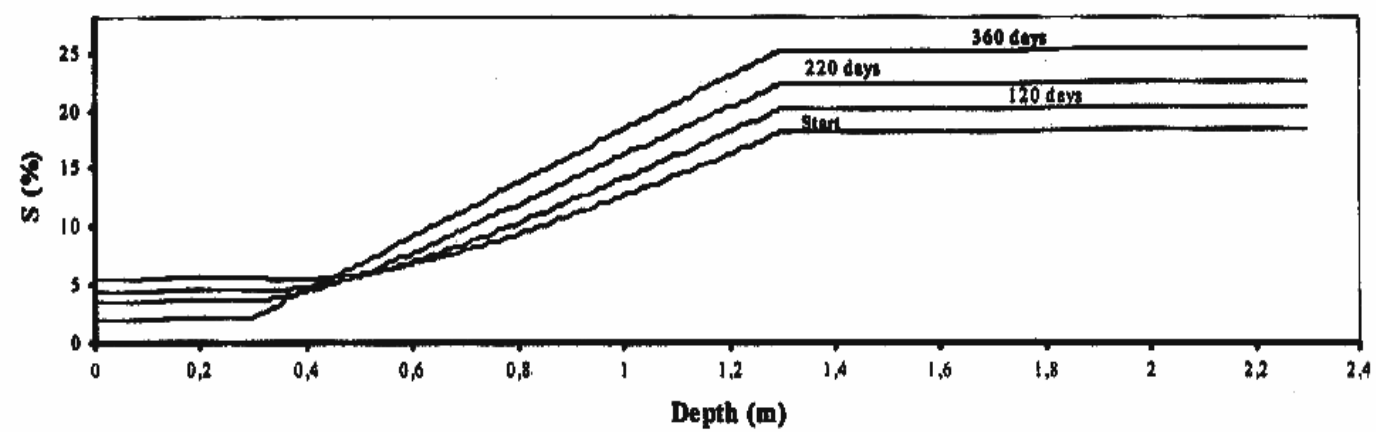

Fig. 4: Solar pond salinity development

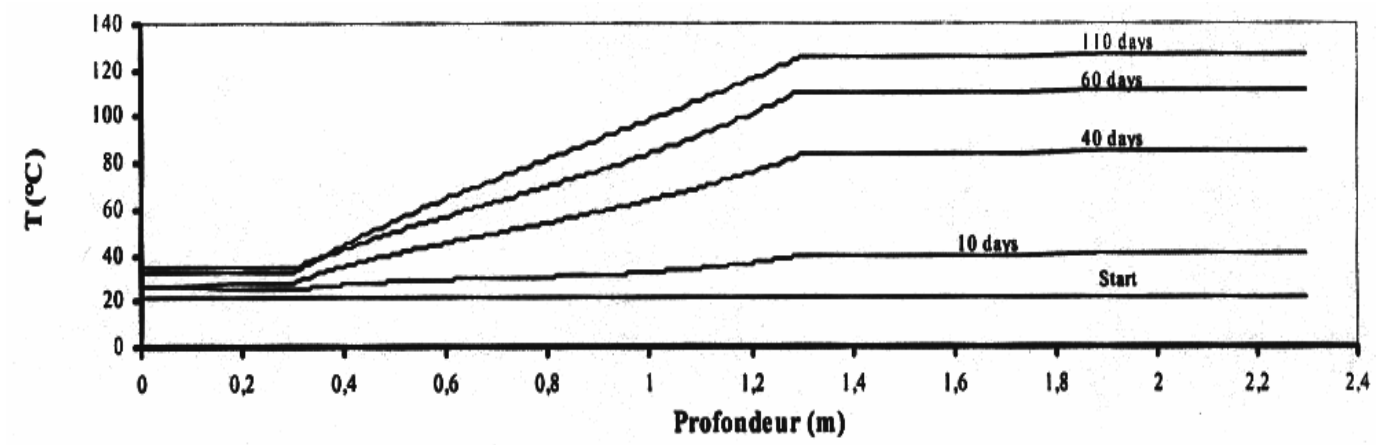

Fig. 5: Solar pond temperature development

Figure 6 shows the density stability ratio $\mathrm{R} \rho$ calculated at the lower interface. The surface was washed continuously to maintain an average salinity of $2 \%-3 \%$ in the upper surface layer and the resupply of brine required to the storage zone was done at a rate of $910^{-9} \mathrm{~m} / \mathrm{s}$ in order to maintain the salinity of the LCZ near saturation. Zangrando [17] assert that equilibrium at the interface occurs when $R \rho=\tau^{-1 / 2}$. For smaller values of $\mathrm{R} \rho$ erosion of the gradient results, and larger $\mathrm{R} \rho$ results to gradient growth. It can be seen that the margin of stability did not go below 10 at the lower interface. To prevent the formation of internal convective zones it is essential to maintain a sufficiently high level of stability within the gradient. An accepted convention is that as long as the margin of stability is greater than 2, the pond is considered to be stable [5]. Calculation shows that $\mathrm{R} \rho$ remains greater than 2 throughout the gradient during one year.

Overheating of storage zone can reduce the stability of the gradient. Any increase in heat storage zone temperature will strengthen the temperature gradient. It is therefore essential to extract enough heat to maintain the storage zone temperature within the desired range. In figure 7 the temperature variation at the bottom of the pond is plotted versus time in the case of a useful heat removal. In the same figure moving mean efficiency is shown. The efficiency was calculated as the ratio of the total heat extracted to the total solar radiation available during a period of one week. It appears that $15 \%$ - $30 \%$ efficiency could have been expected if heat extracted was performed routinely, especially when one considers that the storage temperature is within $40-80{ }^{\circ} \mathrm{C}$. During 70 days the pond is allowed to warm up with no heat removal. Heat extraction occurred when the temperature of the bottom of the pond reached $85^{\circ} \mathrm{C}$. Note that the temperature of the storage zone decreases enormously when the efficiency is high. 


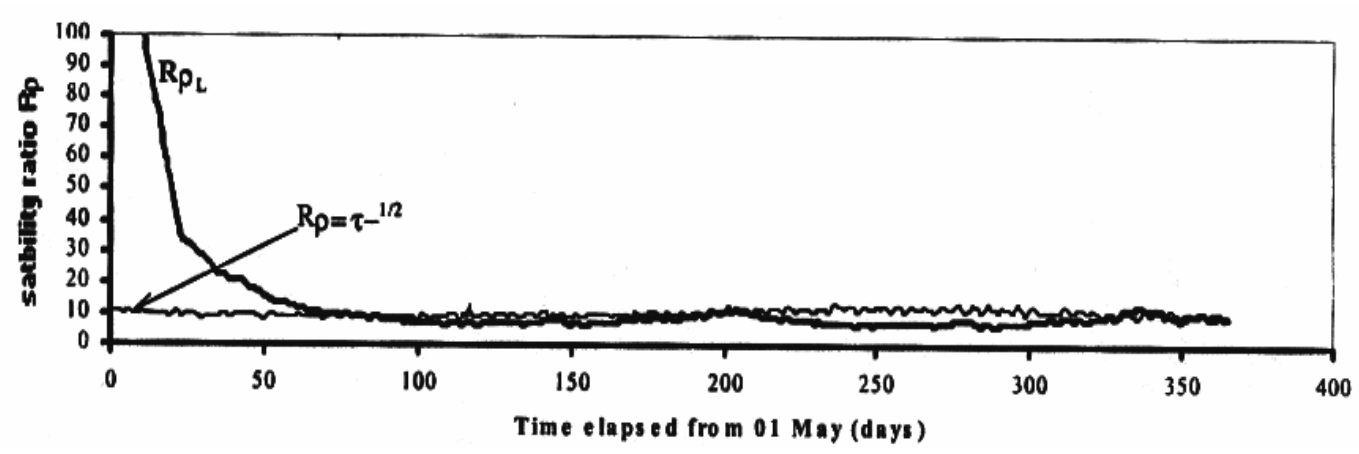

Fig. 6: Stability of the lower and upper interfaces

$$
\begin{aligned}
& \mathrm{R} \rho=\tau^{-1 / 2} \text { for equilibrum } \\
& \mathrm{R} \rho>\tau^{-1 / 2} \text { means entrainment } \\
& \mathrm{R} \rho<\tau^{-1 / 2} \text { means detrainment }
\end{aligned}
$$

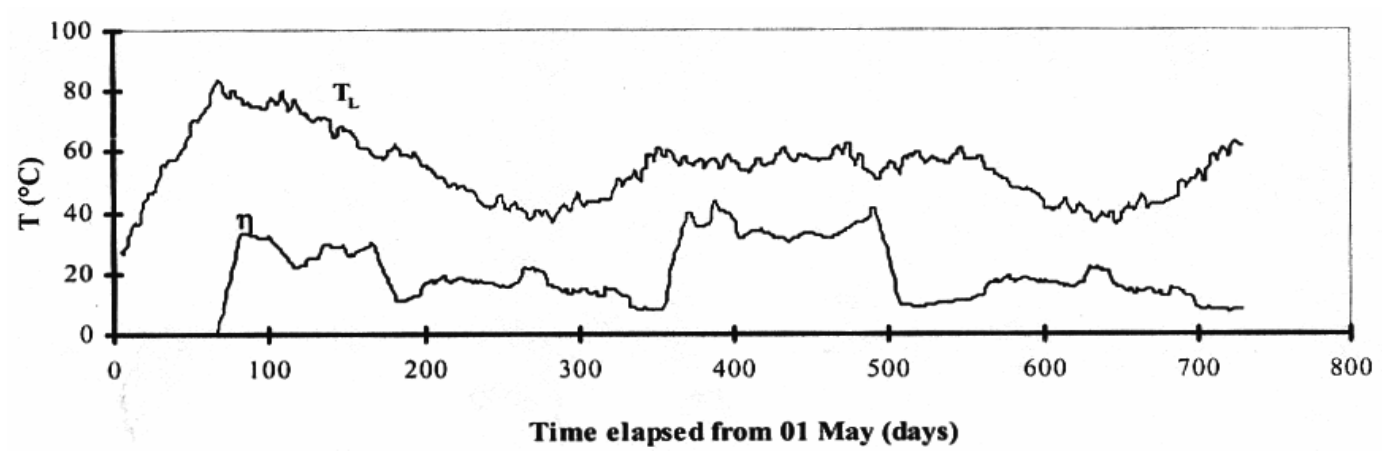

Fig. 7: $\eta=$ Mean weekly efficiency of solar pond in El Bibane $\mathrm{T}_{\mathrm{L}}=$ Temperature of the LCZ

\section{CONCLUSION}

Theoretical performance of a large SP in El Bibane in the southern part of Tunisia is studied for several different cases of interest. A model of a CCSGSP was developed to ensure successful year round operation of the pond. This model was used to study the response of SP to various control techniques. It takes into account heat and salt diffusion in the pond and simulates the transient behaviour of a SGSP in El Bibane in the south of Tunisia. Using linear salinity profile as an initial condition, three-year simulations were run using average meteorological data with the result that adequate stability $(\mathrm{R} \rho>2)$ throughout the gradient and $\mathrm{R} \rho \cong 10$ at the interfaces) was maintained and during the entire year.

Under meteorological conditions, a SP can be effectively controlled by making decisions based on the current state of the pond. The results show that successful operation of a SP requires three things : the maintenance of the storage zone temperature through heat extraction and brine injection, the use of surface washing to control the deepening of the upper mixed layer and a well designed initial salt stratification to prevent the formation of instability within the gradient. They show also that SPs are reliable source of heat for industrial and thermal processes such as desalination in the south of Tunisia. An important load can be served in this climate at temperature appropriate for practical applications. It appears that $15 \%-30 \%$ efficiency could have been expected if heat extracted was performed routinely, especially when one considers that the storage temperature is within $40-80^{\circ} \mathrm{C}$.

\section{REFERENCES}

[1] F.B. Alagao, 'Simulation of the Transient Behaviour of a Closed-Cycle Salt-Gradient Solar Pond', Solar Energy, Vol. 56, N³, pp. 245260, 1996.

[2] M. Giestas, H. Pina and A. Joyce, 'The Influence of Radiation Absorption on Solar Pond Stability', Solar Energy, Vo.1 42, 1996.

[3] M. Hassairi, M.J. Safi and S. Chibani, 'Natural Brine Solar Pond : an Experimental Study', Solar Energy, Vol. 70, 1, pp. 45-50, 2001.

[4] J.R. Hull and C. Nielsen, 'Steady State Analysis of the Rising Solar Pond', Solar Energy, Vol 42, 1989. 
[5] V. Kishore and A. Kumar, 'Solar Pond : an Exercise in Development of Indigenous Technology at Kutch, India', Energy for Sustainable Development, 3, 1, pp. 17-28, 1996.

[6] M. Ouni, A. Guizani and A. Belghith, 'Simulation of the Transient Behaviour of a Salt Gradient Solar Pond in Tunisia', Renewable Energy, Vol. 14, N¹-4.1, 1998.

[7] M. Ouni, A. Guizani and A. Belghith, 'Simulation du Fonctionnement d'un Cycle Fermé d'un Bassin Solaire à Gradient de Sel au Sud Tunisien', Physical and Chemical News, Vol. 4, 2001.

[8] S.V. Patankar, 'On the Hydrodynamics of Salt Gradient Solar Pond', Hemisphere Publishing Corporation.

[9] A. Rabl and C.E. Nielson, 'Solar Ponds for Space Heating', Solar Energy, Vol. 17, 1975.

[10] B.S. Sherman and Y. Imberger, 'Control of a Solar Pond', Solar Energy, Vol. 46, N’2, pp. 71-81, 1991.

[11] B.S. Sherman, 'Modelling and Control of a Solar Pond', Thesis University of Western Australia, 1989.

[12] K. Sreenivas, H. Jaywant, A. Arakeri and J. Srinivisan, 'Modelling the Dynamics of the Mixed Layer in Solar Ponds', Solar Energy, Vol.54, pp.193-202, 1994.

[13] H. Tabor, 'Solar Pond', Solar Energy, Vol. 2, pp. 181-197, 1981.

[14] Wang and Yagoobi, 'Effect of Water Turbidity on Thermal Performance of a Salt Gradient Solar Pond in Greece', Solar Energy, Vol. $54, \mathrm{~N}^{\circ} 5,1993$.

[15] H. Weinberger, 'The Physics of the Solar Pond', Solar Energy, Vol. 8, pp. 45-56, 1964.

[16] Xu, 'Dynamical Process on Salt Gradient Solar Pond', Thesis Univ. of New Mexico

[17] F. Zangrando, 'On the Hydrodynamics of Salt Gradient Solar Pond', Solar Energy, Vol. 46, Nº6, pp. 323-341, 1991.

\section{NOMENCLATURE}

$\begin{array}{ll}\text { A } & \text { Surface of solar pond }\left(\mathrm{m}^{2}\right) \\ \mathrm{C}_{\mathrm{p}} & \text { Specific heat }\left(\mathrm{J} / \mathrm{kg}^{\circ} \mathrm{C}\right) \\ \mathrm{C} & \text { Concentration of salt }\left(\mathrm{kgm}^{-3}\right) \\ \mathrm{D} & \text { Solutal diffusivity }\left(\mathrm{m}^{2} / \mathrm{s}\right) \\ \mathrm{E} & \text { Evaporation }(\mathrm{m} / \mathrm{s}) \\ \mathrm{H}_{\mathrm{SP}} & \text { Depth of the solar pond, (m) } \\ \mathrm{H}_{\mathrm{EP}} & \text { Depth of the solar pond, (m) } \\ \mathrm{H}_{1} & \text { Depth of the UCZ, (m) } \\ \mathrm{H}_{2} & \text { Depth of the NCZ, (m) } \\ \mathrm{H}_{3} & \text { Depth of the LCZ, (m) } \\ \mathrm{I} & \text { Full radiation incident upon the water } \\ & \text { surface }\left(\mathrm{W} / \mathrm{m}^{2}\right) \\ \phi & \text { Rate of thermal energy } \\ \phi_{\text {conv }} & \text { Rate of thermal energy loss due to } \\ \phi_{\mathrm{eva}} & \text { convection }(\mathrm{W}) \\ \phi_{\mathrm{ra}} & \text { Rate of thermal energy loss due to } \\ \phi_{\mathrm{VL}} & \text { evaporation }(\mathrm{W}) \\ \mathrm{R} \rho & \text { Rate of thermal en0ergy loss due to } \\ \mathrm{S} & \text { back radiation to the sky (W) } \\ \mathrm{t} & \text { Rate thermal energy due to a net upward } \\ \mathrm{T} & \text { movement of the NCZ }\end{array}$

$\begin{array}{cl}\mathrm{U}_{\mathrm{v}} & \text { Wind speed } \\ \mathrm{X} & \text { Depth measured from the surface } \\ \mathrm{V} & \text { Net vertical velocity of the SP }(\mathrm{m} / \mathrm{s}) \\ \rho & \text { Density of salt water } \\ \theta & \mathrm{T}-\mathrm{T}_{\mathrm{amb}} \\ \kappa_{\mathrm{T}} & \text { Thermal diffusivity }\left(\mathrm{W} / \mathrm{m}^{\circ} \mathrm{C}\right) \\ \tau & \text { Lewis number } \\ & \text { Subscripts } \\ \mathrm{amb} & \text { Ambient } \\ \mathrm{diff} & \text { Diffusion } \\ \mathrm{e} & \text { Extraction } \\ \mathrm{ep} & \text { Evaporation pond } \\ \mathrm{sp} & \text { solar pond } \\ \mathrm{fw} & \text { fresh water } \\ \mathrm{g} & \text { Ground } \\ \mathrm{i} & \text { Injection } \\ \mathrm{L} & \text { LCZ } \\ \mathrm{j} & \text { number of the sublayers in } \mathrm{NCZ} \\ \mathrm{U} & \text { make water } \\ & \text { UCZ }\end{array}$

